\title{
Reduction of breath alcohol levels in healthy subjects by Citoethyl
}

\author{
Antonelli F. ${ }^{1}$, Ferorelli P. ${ }^{2}$, De Martino A. ${ }^{1,2}$, Beninati S..$^{1, *}$ \\ ${ }^{1}$ University of Rome “Tor Vergata” Department of Biology, Rome, Italy \\ ${ }^{2}$ IURS Santa Rita, Rome, Italy
}

\section{Email address:}

beninati@bio.uniroma2.it(Beninati S.)

\section{To cite this article:}

Antonelli F., Ferorelli P., De Martino A., Beninati S. Reduction of Breath Alcohol Levels in Healthy Subjects by Citoethyl. International Journal of Nutrition and Food Sciences, Vol. 2, No. 4, 2013, pp. 196-199. doi: 10.11648/j.ijnfs.20130204.16

\begin{abstract}
The level of alcohol in the blood is a problem not only for health but also for motorists during the driving. The search for dietary supplements capable of reducing the rate of alcohol was hectic and different products with dubious quality have been put on the market. In the present work, 60 healthy male individuals were subjected to two tests. The first included the administration of $15 \mathrm{~mL}$ of concentrated commercial mixture of vitamins and antioxidants called Citoethyl (CTH), 40 minutes prior drinking $80 \mathrm{~mL}$ of pure ethyl alcohol diluted in $200 \mathrm{~mL}$ of water. The second test was performed by administering $15 \mathrm{~mL}$ of concentrated $\mathrm{CTH}, 40$ minutes after drinking $80 \mathrm{~mL}$ of pure ethyl alcohol diluted in $200 \mathrm{~mL}$ of water. The amount of alcohol ingested corresponded to $1600 \mathrm{~mL}$ of beer ( $5 \% \mathrm{v} / \mathrm{v}$ alcohol) or $535 \mathrm{~mL}$ of wine $(15 \% \mathrm{v} / \mathrm{v}$ alcohol) or $200 \mathrm{~mL}$ of liquor $(40 \% \mathrm{v} / \mathrm{v}$ alcohol). The breath alcohol test was performed on each individual in six ranges of time from the administration of alcohol. We report in this work that there is a net reduction of the breath test value for alcohol resulting from the intake of $\mathrm{CTH}$, in all the conditions used for experimentation. Not guaranteeing the results presented for higher doses of alcohol and for a too short period of time of administration of the CTH. The present work does not pretend to suggest a product for making drunk driving safer, but simply reports the experimental data on a mixture of vitamins and antioxidants, that show its qualities in reducing the rate of breath alcohol levels in healthy subjects.
\end{abstract}

Keywords: Breath Alcohol Test, Antioxidants, Dietary Supplements, Vitamins, Citoethyl

\section{Introduction}

Dietary supplements for alcoholic drinkers are often necessary to replenish any nutrients that alcohol may be leeching from the body [1]. Although carbohydrates and fats are important for vigorous exercise, the ethanol inside alcohol - which is formed by the fermentation of sugar has very little nutritional value at all. To metabolizing alcohol, the liver needs about 1 hour to fully metabolize $8 \mathrm{~g}$ of alcohol. Alcohol can suppress glucose production inside the liver, and increase the risk of hypoglycemia. Hence, it is crucial to always keep a balanced and healthy diet when you drink alcohol and take vitamins to make sure your liver and body are fully prepared to handle the metabolism of ethanol. The best way to avoid the dangers of the use of alcoholic beverages is to take specific dietary supplements [2]. Many alcoholics are deficient in B vitamins. Recently it was observed that some alcoholics spontaneously stopped drinking in association with taking niacin supplements. It was suggested that alcoholism might be a manifestation of niacin deficiency in some people and recommended that alcoholics should consider supplementation with $500 \mathrm{mg}$ of niacin per day [3]. Without specifying the amount of niacin used, preliminary research findings suggested that niacin supplementation helped wean some alcoholics away from alcohol [4]. Activated vitamin B3 used intravenously has also helped alcoholics quit drinking [5]. Niacin amide, a safer form of the same vitamin [6], might have similar actions and has been reported to improve alcohol metabolism in animals [7]. Deficiencies of other Bcomplex vitamins are common with chronic alcohol use [8]. The situation is exacerbated by the fact that alcoholics have an increased need for B vitamins [9]. It is possible that successful treatment of B-complex vitamin deficiencies may actually reduce alcohol cravings, because animals crave alcohol when fed a B-complex-deficient diet [10]. Although the incidence of B-complex deficiencies is known to be high in alcoholics, the incidence of other vitamin deficiencies remains less clear [11]. Nonetheless, deficiencies of vitamin $\mathrm{A}$, vitamin $\mathrm{D}$, vitamin $\mathrm{E}$, and 
vitamin $\mathrm{C}$ are seen in many alcoholics. While some reports have suggested it may be safer for alcoholics to supplement with beta-carotene instead of vitamin A [12], potential problems accompany the use of either vitamin A or betacarotene in correcting the deficiency induced by alcoholism [13]. These problems result in part because the combinations of alcohol and vitamin A or alcohol and betacarotene appear to increase potential damage to the liver. Thus, vitamin A-depleted alcoholics require a doctor's intervention, including supplementation with vitamin $\mathrm{A}$ and beta-carotene accompanied by assessment of liver function. Supplementing with vitamin $\mathrm{C}$, on the other hand, appears to help the body rid itself of alcohol [14]. The aim of this study was to investigate the preventive effects of a commercial mixture of vitamins and antioxidants called Citoethyl $(\mathrm{CTH})$ on the reduction of breath alcohol test levels in healthy subjects of different age

\section{Material and Methods}

60 healthy male subjects were used in a 6 age intervals $(18 / 24,25 / 32,33 / 43,44 / 50,52 / 60,62 / 70$ - 10 subjects for each age, free of diseases and of any therapeutic treatments). Each of them was subjected to two tests. The first included the administration of $15 \mathrm{~mL}$ of concentrated $\mathrm{CTH}, 40$ minutes prior drinking $80 \mathrm{~mL}$ of pure ethyl alcohol diluted in $200 \mathrm{~mL}$ of water. The second test was performed by administering $15 \mathrm{~mL}$ of concentrated $\mathrm{CTH}$, 40 minutes after drinking $80 \mathrm{~mL}$ of pure ethyl alcohol diluted in $200 \mathrm{~mL}$ of water. The amount of alcohol ingested corresponded to $1600 \mathrm{~mL}$ of beer ( $5 \% \mathrm{v} / \mathrm{v}$ alcohol) or 535 $\mathrm{mL}$ of wine $(15 \% \mathrm{v} / \mathrm{v}$ alcohol) or $200 \mathrm{~mL}$ of liquor $(40 \% \mathrm{v}$ / $\mathrm{v}$ alcohol). The breath alcohol test was performed on each individual in six ranges of time (30 minutes, 1, 2, 3, 4, 5 hours) from the administration of alcohol by a BACtrack Select S80 Breathalyzer Professional Edition (BACtrack, S.Francisco, CA). The commercial mixture of vitamins and antioxidants (Citoethyl) was a gift from Citozeatec (Citozeatec S.r.l. Peschiera Borromeo, Milano, Italy). The main components of CTH are as follows (units/100 g): 500 $\mathrm{mg}$ of vitamin C, $56 \mathrm{mg}$ of vitamin B5, $56 \mu \mathrm{g}$ of vitamin D, $3,3 \mathrm{mg}$ of vitamin B9, $222 \mathrm{mg}$ of pyruvic acid, $120 \mathrm{mg}$ of citric acid, $250 \mathrm{mg}$ of tartaric acid and $77.8 \mathrm{~g}$ of carbohydrates.

\subsection{Statistical Analyses}

The statistical analysis was performed using the MannWhitney U test for intergroup comparisons. Spearman's rank correlation test and the linear regression analysis were performed to analyze correlations among age groups and the type of administration of $\mathrm{CTH}$ and to draw least squares regression lines. Values were expressed as the mean of three measurements. The variability of the data was of about $20 \%$.

\section{Results}

Fig. 1 shows the results of the preventive administration of CTH $(15 \mathrm{~mL})$ to 60 volunteers aged between 18/24 and $62 / 75$ years old, 40 minutes before the administration of 80 $\mathrm{ml}$ of pure ethyl alcohol. Data are expressed as a reduction of the values obtained on breath alcohol test at the designated time and calculation of the percentage reduction compared with control subjects. Of particular interest are the data for the age groups between 18-24 and 25-32 years. The data obtained in this age range show that two hours after the administration of alcohol, the values obtained on breath alcohol test was reduced by about 50-60\%. In older subjects the values obtained were lower probably due to a delayed liver catabolism of alcohol. Analyzing the values obtained in the age range $62 / 75$ it is clear a noticeable reduction in the effect of the CTH only at 4-5 hours after administration of alcohol. Fig. 2 shows the results of the administration of CTH $(15 \mathrm{~mL})$ at 60 volunteers between $18 / 24$ and $62 / 75$ years old, 40 minutes after the administration of $80 \mathrm{ml}$ of pure ethyl alcohol. Data are expressed as a reduction of the values obtained on breath alcohol test at the designated time and the calculation of the percentage reduction compared with control subjects. In this case data relating to individuals of age between 18-24 and 25-32 years, undergo a significant reduction and in particular to two hours from taking alcohol the percentage of reduction of the breath alcohol test, reaches values between 64 and $70 \%$. Also in this case the values obtained were lower in elderly subjects compared to younger subjects, but higher than those obtained for the preventive administration of CTH (Fig. 1).

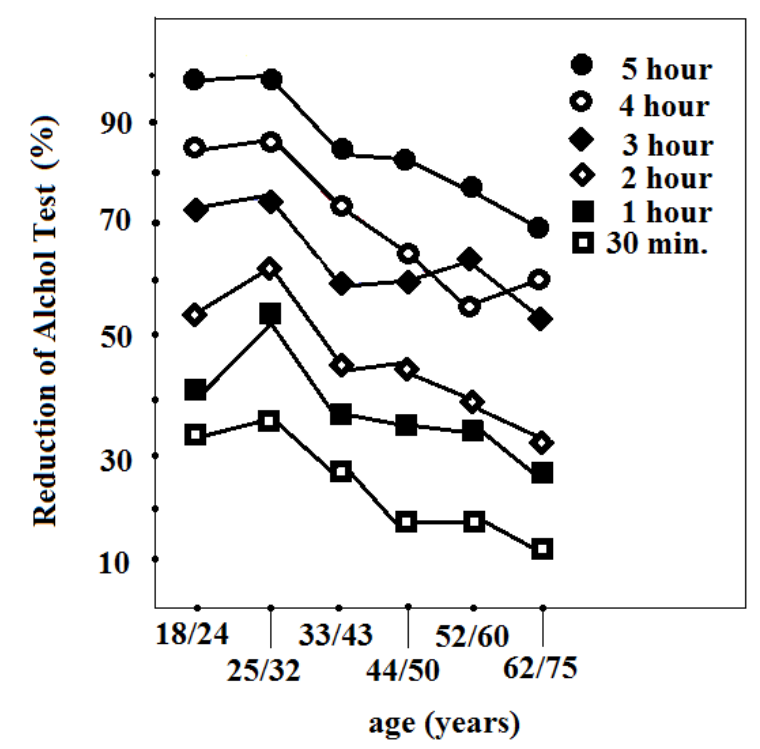

Figure 1. Test with CTH $(15 \mathrm{~mL})$ given 40 minutes before the assumption of $80 \mathrm{~mL}$ of pure alcohol. Percentage of reduction of values of breath alcohol test, performed on healthy individuals at several hours, respect to control. Data are the mean of three determinations.

In evaluating these data it is essential to consider the natural reduction of breath alcohol test values that occurs 
during the time of the experiment. In fact it is useful to note that the values to 5 hours are close to $100 \%$ in both tests. In conclusion appears to be more effective to take the CTH after the consumption of alcohol at the indicated concentrations.

\section{Discussion}

All alcoholic drinks are psychoactive, and therefore capable of acting on the central nervous system of the individual who takes them, altering the normal behavior, such as alertness, attention and concentration. Therefore also act negatively on the ability to drive a car, turning the individual into an extreme danger to himself and others. In the last twenty years, it has extended the intake of alcoholic beverages among adolescents [15]. In the female gender, alcohol consumption may represent a greater danger, considering that unlike men, women are particularly sensitive to alcohol due to a reduced activity of the enzyme alcohol dehydrogenase [16]. Added to this is an increased vulnerability as a function of physiological conditions such as pregnancy and lactation[17-19].

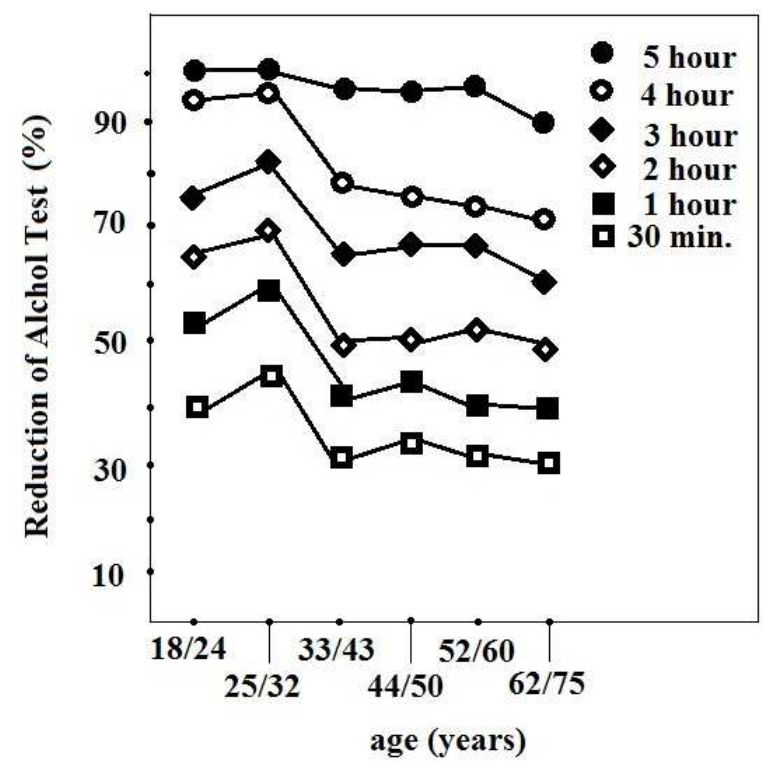

Figure 2. Test with CTH $(15 \mathrm{~mL})$ given 40 minutes after the assumption of $80 \mathrm{~mL}$ of pure alcohol. Percentage of reduction of values of breath alcohol test performed on healthy individuals at several hours, respect to control. Data are the mean of three determinations.

Considering the individual variability, it is not possible to identify the recommended amount of alcohol consumption, which is considered "safe" for health. To this end it would be more appropriate to suggest quantity "low risk", noting that the risk exists at any concentration by volume and increases progressively with the increase in the quantity of alcoholic beverages consumed [20]. It is important to remember that under the age of 16 years the law prohibits the consumption of alcoholic beverages, and in any case below that age do not drink is the best choice for health and safety. To this end, we suggest, in cases in which occurs a non-controlled intake of alcohol and prior to driving of motor vehicles, to carry out an alcohol test for assessing the concentration of alcohol present in the blood. If the alcohol proves higher than the parameters of the law, it is recommended to take $\mathrm{CTH}$ in vials of $15 \mathrm{ml}$, orally, diluted in water. They can be taken up to 2 vials for a total of $30 \mathrm{ml}$ of product. We want to emphasize that this product is not intended to make drunk driving safer.

The CTH produced by Citozeatec Ltd., was authorized by the Ministry of Health, it aims to contribute to the reduction of blood alcohol, limiting toxic effects. One of the quality that has emerged in the course of the present trial was that $\mathrm{CTH}$ can also reduce the damage of liver due to excessive use of alcohol [21].

We report in this work that there is a net reduction of the values of the breath test for alcohol resulting from the intake of $\mathrm{CTH}$, in all the conditions used for experimentation. Prophylactic administration (40 minutes before the first alcohol intake) becomes effective at a dose of $15 \mathrm{~mL}$ of product. The administration of $\mathrm{CTH}$, after alcohol intake, appears much more effective achieving better results in young people. It is appropriate to recommend the use of the product for alcohol intakes do not exceed the total value and $80 \mathrm{~mL}$ of absolute alcohol ( $1600 \mathrm{ml}$ of beer at $5 \%, 535 \mathrm{~mL}$ of wine at $15 \%$ and about $200 \mathrm{ml}$ of liquor to $40 \%$ ). Not guaranteeing the results presented for higher doses of alcohol and for a too short period of time of administration of the CTH. It is also a good idea to communicate to potential users, that the product accelerates the reduction of the alcohol content, but does not eliminate completely the effects of alcohol. In fact, you should also consider that in the presence of disease or because of the different response to the individual the product may not give the desired results. Overall, it is important to consider that the threat posed by drunk driving comes not from the levels of the breath alcohol test per se but from the impairment drinking can cause.

\section{Acknowledgements}

We thank A.F., president of AIAS (Italian Association of Assistance Spastic) for funding this research.

\section{References}

[1] Guenther RM. Role of nutritional therapy in alcoholism treatment. Int J Biosoc Res 1983;4:5-18.

[2] Biery JR, Williford JH \& McMullen EA. Alcohol craving in rehabilitation: assessment of nutrition therapy. J Am Diet Assoc 1991;91:463-466.

[3] Cleary JP. Etiology and biological treatment of alcohol addiction. J Neuro Ortho Med Surg 1985;6:75-77.

[4] Smith RF. A five-year field trial of massive nicotinic acid therapy of alcoholics in Michigan. J Orthomolec Psychiatry 1974;3:327-331. 
[5] O'Halloren P. Pyridine nucleotides in the prevention, diagnosis and treatment of problem drinkers. West J Surg Obstet Gynecol 1961;69:101-104.

[6] Cosmetic Ingredient Review Expert Panel. "Final report of the safety assessment of niacinamide and niacin." Int J Toxicol. 2005;24 Suppl 5:1-31.

[7] Eriksson CJP. Increase in hepatic NAD level its effect on the redox state and on ethanol and acetaldehyde metabolism. Fed Eur Biochem Soc 1974;40:3117-3120.

[8] Baker H. A vitamin profile of alcoholism. Int J Vitam Nutr Res 1983;(suppl 24):179.

[9] Schuckit MA. Alcohol and Alcoholism. In: Fauci AS, Braunwald E, Isselbacher KJ, et al, eds, Harrison's Principles of Internal Medicine, 14th ed. New York: McGraw-Hill, 1998, 2503-2508.

[10] Norton VP. Interrelationships of nutrition and voluntary alcohol consumption in experimental animals. $\mathrm{Br} \mathrm{J}$ Addiction 1977;72:205-212.

[11] Morgan MY \& Levine JA. Alcohol and nutrition. Proc Natl Acad Sci 1988;47:85-98.

[12] Chapman K, Prabhudesai M, Erdman JW. Vitamin A status of alcoholics upon admission and after two weeks of hospitalization. J Am Coll Nutr 1993;12:77-83.

[13] Leo MA \& Lieber CS. Alcohol, vitamin A, and betacarotene: adverse interactions, including hepatotoxicity and carcinogenicity. Am J Clin Nutr 1999;69:1071-1085 [review].

[14] Chen M, Boyce W \& Hsu JM. Effect of ascorbic acid on plasma alcohol clearance. J Am Coll Nutr 1990;9:185-189.

[15] Yuma-Guerrero PJ, Lawson KA, Velasquez MM, von Sternberg K, Maxson T \& Garcia N. Screening, brief intervention, and referral for alcohol use in adolescents: a systematic review.Pediatrics. $2012 ; 130(1): 115-122$.

[16] Frezza M, DiPadova C, Pozzato G, Terpin M, Baraona E \& Lieber CS High blood alcohol levels in women: The role of decreased gastric alcohol dehydrogenase and first-pass metabolism. New England J Medicine 1990:322(2):95-99.

[17] Heil SH, Hungund BL, Zheng ZH, Jen KL \& Subramanian MG. Ethanol and lactation: Effects of milk lipids and serum constituents. Alcohol 1999; 18: 43-48.

[18] Mennella JA \& Pepino MY. Breastfeeding and prolactin levels in lactating women with a family history of alcoholism. Pediatrics. 2010;125(5):e1162-1170.

[19] Pearson RM, Heron J, Melotti R, Joinson C \& Evans J. The impact of alcohol use during pregnancy on maternal responses after birth. Arch Womens Ment Health. 2012;15(6):433-443.

[20] Bissett S, Wood S, Cox R, Scott D, \& Cassell J. Calculating alcohol risk in a visualization tool for promoting healthy behavior. Patient Educ Couns. 2013:Jun 3. doi:pii: S07383991(13)00169-9.

[21] Torricelli P., Ferorelli P., De Martino A., Antonelli F \& Beninati S. The Influence of preventive multiple micronutrients supplementation on Liver Steatosis in HighCholesterol Fed C57BL6/N mice. American Journal of Life Sciences. 2013: 1(2);55-60. 